\title{
Monarquias cristãs \\ na Escandinávia \\ medieval: as \\ relações de poder \\ na Óláfs saga \\ Tryggvasonar de \\ Oddr Snorrason
}

\section{Guilherme Tavares Lopes Balau* Rodrigo Kmiecik $^{* *}$}

DOI: 10.11606/issn.2318-8855.v10i2p624-647

Resumo: O objetivo deste trabalho é analisar a formação das monarquias cristãs e as relações de poder na Escandinávia medieval, especificamente na Noruega e na Islândia. Para tal propósito, utilizamos como fonte a Saga de Olaf Tryggvason (óláfs saga Tryggvasonar), escrita pelo monge islandês Oddr Snorrason ao final do século XII. A abordagem é norteada pela Vorstellungsgeschichte (história das concepções), metodologia desenvolvida pelo historiador alemão Hans-Werner Goetz. Deste modo, buscamos compreender a percepção do passado que Oddr Snorrason demonstra na saga, suas noções de poder político e religioso, bem como a construção de Olaf Tryggvason como um modelo régio. Assim, demonstramos como essas relações de poder foram percebidas, significadas e registradas na Idade Média.

Palavras-chaves: Cristianização; Escandinávia medieval; Olaf Tryggvason; Saga islandesa.

* Guilherme Tavares Lopes Balau é graduando em História pela Universidade Estadual de Londrina (UEL), orientado pelo professor Dr. Lukas Gabriel Grzybowski. E-mail: guilherme.tavares@uel.br

** Rodrigo Kmiecik é graduando em História pela Universidade Estadual de Londrina (UEL), orientado pelo professor Dr. Lukas Gabriel Grzybowski. E-mail: rodrigo.kmiecik@uel.br 


\section{O Poder na Idade Média}

\section{Monarquias cristãs na Escandinávia medieval}

\section{Introdução}

O início da evangelização da Escandinávia como uma empreitada institucional pode ser estabelecido a partir dos primeiros esforços dos chamados bispos missionários, Ansgar e seu sucessor Rimbert, sob o apoio da arquidiocese de HamburgoBremen. Ao se debruçarem sobre as fontes referentes a este período, os historiadores mostraram que as missões empreendidas por Ansgar e Rimbert no século IX não tiveram grandes resultados ${ }^{1}$. Com efeito, as próprias conclusões de Rimbert, ao escrever sobre seu mestre Ansgar, são as de que ainda havia muito trabalho a ser feito. Ao longo dos séculos X e XI, os ímpetos continuaram, com menor ou maior fôlego, em diversos âmbitos que cruzavam as esferas eclesiástica e régia. O processo de cristianização culmina na conversão dos reis ao longo do século XI, ponto que marca o que os historiadores vão entender como a consolidação deste lento e longo processo².

Desse período mais tardio em diante, uma tradição escrita na região escandinava cresce, marcada especialmente por hagiografias, poesia escáldica e pelas sagas islandesas. Nesse trabalho, buscamos entender as percepções do monge Oddr Snorrason, autor da Saga de Olaf Tryggvason (Óláfs saga Tryggvasonar), a respeito do rei Olaf e seus êxitos como rei missionário. Nossos esforços foram direcionados a enten-

\footnotetext{
${ }_{1}^{1}$ Para mais detalhes ver os trabalhos de PALMER, James. Rimbert's Vita Anskarii and Scandinavian Mission in the Ninth Century; MELLOR, Scott. St Ansgar: His Swedish Mission and Its Larger Context.

${ }^{2}$ Sobre os conceitos de cristianização e conversão ver WINROTH, Anders. The conversion of Scandinavia: Vikings, merchants, and missionaries in the remaking of Northern Europe; KMIECIK, Rodrigo. As comunidades cristãs prévias à consolidação do corpo eclesiástico na Escandinávia medieval. Na historiografia brasileira, especialmente na última década, surgiram diversos trabalhos sobre o longo processo de evangelização da Escandinávia, suas muitas fases e sua interpretação nas fontes históricas. Ver GRZYBOWSKI, Lukas. O início da missão cristianizadora da Escandinávia e sua interpretação nas Gesta Hammaburgensis de Adam de Bremen; QUINTANA, Tiago; BRAGANCA JR., Álvaro Alfredo. A cristianização da Noruega e o fortalecimento da monarquia norueguesa - uma perspectiva histórico-literária; BIRRO, Renan. Rex Perpetuus Norvegiae: A sacralidade régia na monarquia norueguesa e a santificação de Óláfr Haraldsson (c. 995-1030) à luz da literatura nórdica latina e vernacular (sécs. XI-XII) - dissertação de mestrado.
} 


\section{O Poder na Idade Média}

\section{Guilherme Tavares Lopes Balau e Rodrigo Kmiecik}

der como Oddr utiliza o passado na sua produção textual, tendo escrito sobre Olaf Tryggvason (rei da Noruega de 995 a 1000) no final do século XII, quase duzentos anos após a morte do monarca.

Para fins práticos, selecionamos os capítulos S22, S23 e S24 da saga, na tradução para o inglês feita por Theodore M. Andersson. Esses capítulos só existem em um manuscrito preservado em Estocolmo, na Suécia. Partindo desse recorte, visamos entender os vínculos do âmbito político e do âmbito religioso nas relações de poder presentes na saga.

\section{A materialidade do passado}

Para compreender a relevância de um estudo focado no fenômeno da escrita da história, é necessário ter em mente para que serve a narrativa histórica. Toda escrita da história, bem como sua concepção pelo leitor, é uma ocorrência do presente. O trabalho dos historiadores medievais sempre extrapola o anseio humanístico de manutenção da memória. Seja em narrativas de caráter intencional ou de caráter indireto, como em tratados de lei e epístolas, a intenção que permeia essas narrativas se mostra ao historiador contemporâneo como parte da ideologia do autor, representante da consciência comum ao período histórico em questão. Além de discursar sobre o que outrora aconteceu, o historiador medieval transmite suas crenças, convicções e visões de mundo. A representação do passado parte de um processo de criação que atribui sentido baseado nas expectativas dos sujeitos históricos, em uma espécie de orientação por assenhoramento do passado (RÜSEN, 2001, p. 30).

Este é um processo dinâmico que se forma a partir de uma consciência da história [Geschichtsbewußtsein] e de um conceito de história [Geschichtsbild], ideias-chave 


\section{O Poder na Idade Média}

\section{Monarquias cristãs na Escandinávia medieval}

para a análise da história das concepções [Vorstellungsgeschichte] ${ }^{3}$. Enquanto o conceito de história trata de um processo de simplificação de eventos históricos para um entendimento mais prático da realidade passada, a consciência histórica parte da noção de historicidade e mudança histórica, da concepção de história como processo e dos interesses intrínsecos a ela. Esses aspectos correspondem à expectativa ideológica atribuída ao passado e encontram-se refletidos na historiografia de quaisquer períodos.

Dessa maneira, compreender como se constrói a historiografia medieval pode iluminar os interesses do presente sobre o passado, de maneira que a concepção de poder e legitimidade política possui forma na materialização da narrativa de seu autor.

No prólogo da Saga de Olaf Tryggvason, o monge Oddr Snorrason afirma que a obra possui um valor hierárquico superior ao da simples narrativa do senso-comum sobre o período do reinado de Olaf. Segundo Oddr, esse senso-comum é caracterizado por "contos de madrastas narrados por jovens pastores" (2003, p. 35, tradução própria) ${ }^{4}$. O foco do autor é direcionado à figura do rei e à maneira exemplar de seus atos, que trouxeram a cristandade àquela terra pagã.

A alusão ao passado no período referido deve ser compreendida como uma ação de peso semelhante à lei, em que o passado é um ponto de referência moral para as ações e virtudes do presente, semelhante ao papel desempenhado pelas

\footnotetext{
3 Conforme teorizado em (GOETZ 2003; 2012) e discutido em (GRZYBOWSKI, 2012). A história das concepções se apresenta como outra via de estudo para o pensamento do passado, frente à problemática pós-moderna da virada linguística. Através de uma reavaliação de paradigma, a análise do historiador propõe a busca pela superestrutura ideológica dos sujeitos históricos, em contraste com a tradicional procura pela verificabilidade dos acontecimentos relatados em fontes historiográficas.

${ }^{4}$ No original: "stepmother tales told by shepherd boys".
} 


\section{O Poder na Idade Média}

\section{Guilherme Tavares Lopes Balau e Rodrigo Kmiecik}

narrativas tradicionais dos specula para a instrução de membros da realeza e do clero. Não é "em si" que as representações do passado possuem um fim, mas na ligação que o passado possui com as necessidades do presente, como exposto por HansWerner Goetz:

A percepção do passado não possuía um fim em si mesma, nem na Idade Média nem hoje em dia. [...] A visão do passado tinha o objetivo de enfatizar coerência genética; no entanto, não buscava esse objetivo (como hoje em dia) para pesquisar a formação do presente mas sim para investigar o posicionamento temporal do presente no curso da história universal e da salvação. Além do mais, era uma ferramenta didática que iluminava exemplos de comportamentos corretos (GOETZ, 2003, p. 163-4, tradução própria) ${ }^{5}$

É nesse ponto em que se compreende a contemporaneidade do passado quando se trata do entendimento medieval. Em sua concepção específica sobre a história, os autores medievais vêem uma lógica a ser decifrada, trazendo uma atemporalidade aos fenômenos do passado, na qual os valores transcendem a limitação espaço-temporal.

A historiografia do período analisado pode ser entendida como uma construção do passado; não da literalidade dos acontecimentos, mas de segmentos subjetivos, formados a partir do entendimento dos fatos - todo acontecimento pertinente à formação do conceito de história do narrador - que são reproduzidos a partir de fontes variadas, desde a tradição oral aos documentos legais do período, por vezes já reproduzidos em obras literárias anteriores. A percepção sensível interpreta esses fatos e 'traduz' o passado de acordo com a concepção que o autor possui da

\footnotetext{
${ }^{5}$ No original: "The perception of the past did not have an end in itself, neither in the Middle Ages nor nowadays. [...] The view of the past was intended to emphasize genetic coherence; however, it did not pursue this aim (like nowadays) in order to survey the formation of the present but rather to investigate the temporal position of the present in the course of the universal and salvational history. Moreover, it was a didactic tool that illuminated examples of correct behavior".
} 


\section{O Poder na Idade Média}

\section{Monarquias cristãs na Escandinávia medieval}

realidade, agindo como um filtro de entendimento. Isso gera uma percepção consciente sobre os fatos, subsequentemente afetada pelas variáveis humanas do esquecimento e do entendimento da informação, além da vontade e intenção de enquadrar o que é registrado. Ainda, o testemunho toma sua forma de representação baseada nas tradições literárias e linguísticas dos sujeitos históricos (GOETZ, 2006, p. 18-23).

Essa leitura da realidade empreendida pelos autores medievais não é acrítica. Como é possível deduzir pela hierarquização das fontes de informação pelo autor, havia a possibilidade de um indivíduo transmitir uma narrativa mais crível, ou mais "oficial", de acordo com sua experiência perante os "fatos", o que leva à importância da ponderação sobre a informação e a intenção de comunicar a verdade sobre acontecimentos passados. Ainda assim, é uma leitura presente em uma experiência histórica específica. Enquanto em outros casos não se leva em consideração a intervenção divina nos acontecimentos do passado, essa interpretação era uma possibilidade constante e atribuidora de sentido ao entendimento da história no medievo; o tempo é uma condição natural da vida humana, mas sua medição, percepção e representação são processos sociais e históricos (GOETZ, 2003, p. 140).

A historiadora Pernille Hermann discutiu a preocupação dos islandeses para com sua história e sua memória. Essa autora definiu a memória na Idade Média como uma espécie de armazém [storehouse], no qual as muitas memórias do passado seriam guardadas e preservadas através da escrita, assim superando a barreira que anteriormente a morte impunha aos seus portadores. Entretanto, não são memórias imutáveis:

Os autores medievais recordam o passado de diversas formas, e seu registro das memórias envolvia uma dimensão dinâmica e criativa que não apenas salvava as memórias do esquecimento, mas também organizava as memórias de 


\section{O Poder na Idade Média}

\section{Guilherme Tavares Lopes Balau e Rodrigo Kmiecik}

acordo com necessidades do presente. (HERMANN, 2009, p. 293. tradução própria) ${ }^{6}$

Desse modo, entendemos que essas memórias são preservadas e salvas do esquecimento, e seu armazenamento através do registro textual implica mudanças sobre quaisquer registros. De acordo com os apontamentos de Hermann, as necessidades do presente vão reverberar mais alto que a materialidade do passado, e assim as memórias mostram-se metamórficas conforme as concepções dos autores que as manipulam constantemente. De acordo com o tempo transcorrido, as intenções do autor, omissões conscientes ou não, invenções, diferentes discursos, legitimar ou invalidar certas estruturas sociopolíticas, entre outros fatores, o passado está sempre submetido à sua (re)construção pelo presente.

\section{Oddr Snorrason e o documento}

O trabalho de Oddr Snorrason pode ser compreendido como uma continuação dos esforços empreendidos por Ari Thorgilsson, o Sábio, ao iniciar uma tradição textual da escrita da história na Islândia, tanto em língua vernácula quanto em latim. Santiago Barreiro periodizou a produção textual islandesa de modo que é possível identificar um período inicial, do qual "os exemplos mais antigos datam dos primeiros anos do século XII, mas normalmente encontram-se preservados em manuscritos posteriores" (BARREIRO, 2019, p. 172, tradução própria) ${ }^{7}$. Por mais que a língua vernácula tenha permanecido predominante na poesia escáldica e na maior parte das sa-

\footnotetext{
${ }^{6}$ No original: "Medieval writers remembered the past in more than one way, and their recording of memories also involved a dynamic and creative dimension that not only saved memories from oblivion, but also organized memories according to present needs".

${ }^{7}$ No original: “Los ejemplos más antiguos datan de los primeros años del siglo XII pero se encuentran normalmente preservados en manuscritos posteriores".
} 


\section{O Poder na Idade Média}

\section{Monarquias cristãs na Escandinávia medieval}

gas islandesas, a Saga de Olaf Tryggvason foi composta em latim, no final do século XII, por volta de 1180 .

Segundo Theodore M. Andersson, o manuscrito original foi perdido, restando duas traduções em islandês e o fragmento de uma terceira. A obra é a primeira a possuir as dimensões de uma saga. Ainda de acordo com Andersson, “a forma é estritamente biográfica e, assim, em termos de gêneros literários, se assemelha às vidas de santos, a forma dominante de narrativa em prosa na Islândia do século XII" (ANDERSSON, 2006, p. 25) ${ }^{8}$. Oddr Snorrason foi um monge beneditino no mosteiro de Thingeyrar, norte da Islândia, e sua saga faz parte de uma tradição bastante específica, com ecos hagiográficos.

Durante o século XII aparecem as primeiras obras que se concentram em um único rei. Entre elas, podemos distinguir algumas de forte influência hagiográfica, que lidam com a vida dos dois reis cristãos da Noruega, Olaf Tryggvason e Olaf Haraldsson inn helgi, 'o santo'. (BARREIRO, 2017, p. 166, tradução própria) ${ }^{9}$

Assim, entende-se que os usos do passado empreendidos por Oddr Snorrason em sua obra carregam delimitações que dizem respeito aos feitos de Olaf Tryggvason como rei da Noruega, especialmente motivos narrativos da cristianização, culminando em um desfecho que traz odes heroicas e uma forte analogia ao modelo de mártir hagiográfico. De acordo com Andersson, Olaf Tryggvason “gozava de um status quase oficial como apóstolo do cristianismo na Islândia" (ANDERSSON, 2006, p. 43, tradução própria) ${ }^{10}$, e a saga composta por Oddr Snorrason evidencia essas ideias e contribui

\footnotetext{
${ }^{8}$ No original: "The form is strictly biographical and is therefore, in terms of literary genres, closely akin to the saint's life, the dominant form of prose narrative in twelfth-century Iceland".

${ }^{9}$ No original: "Durante el siglo XII aparecen las primeras obras que se centran en un único rey. Entre ellas podemos distinguir algunas de fuerte influencia hagiográfica, que se ocupan de la vida de los dos reyes cristianizadores de Noruega, Óláfr Tryggvason y Óláfr Haraldsson inn helgi ('el santo')".

${ }^{10}$ No original: "enjoyed some quasi-official status as the apostle of Christianity in Iceland".
} 


\section{O Poder na Idade Média}

\section{Guilherme Tavares Lopes Balau e Rodrigo Kmiecik}

com esforços para a formação de uma consciência histórica a respeito de Olaf e seus êxitos político-religiosos.

Para escrever a saga, Oddr dispôs de algumas fontes. Uma delas foi Ásgrím Vestlidason, abade em Munkathverá, que preservou as informações a respeito de Olaf Tryggvason que datam do início do século XII. Além de Ásgrím, outra importante fonte para Oddr Snorrason foi a eclesiástica Ingunn Arnórsdóttir, pupila do bispo Jón Ögmundsson, provavelmente contemporânea de Ásgrím (ANDERSSON, 2006, p. 26-7). Ambos são listados como as principais fontes de Oddr para redigir a saga, por serem uma ponte entre Oddr Snorrason e o que se sabia por meio de Ari, o Sábio, no século anterior a respeito do rei Olaf Tryggvason. A narrativa se constrói, ainda, sobre outros relatos orais e memórias.

Pelo menos algumas de suas fontes eram clericalmente coloridas e focaram em Olaf como um rei missionário. As fontes mais seculares enfatizam os fatos heroicos de Olaf: por exemplo, os poemas escáldicos de Hallar-Stein, "Rekstefja" e "Óláfsdrápa", possivelmente do final do século XII. Oddr não os teria citado na versão original em latim [da saga] por causa da discrepância linguísti$\mathrm{ca}$, mas ele certamente conhecia esses poemas e suas fontes. Havia, portanto, linhas eclesiásticas e seculares em sua formação. (ANDERSSON, 2006, p. 27, tradução própria) ${ }^{11}$

É necessário pensar nas intenções do autor ao redigir a saga, ao delimitar sua escrita da história com base nas suas intenções, ideias e consciência da história. Há momentos de ação e viés secular, como a construção dos navios de Olaf Tryggvason e a batalha de Svǫlðr, mas entendemos que o poder legitimado na saga, através do passado, é tanto secular quanto religioso. Todas as ações seculares culminam na ideia

\footnotetext{
${ }^{11}$ No original: "At least some of his sources were clerically colored and would have focused on Olaf as a missionary king. The more secular sources emphasized Olaf's heroic feats: for example, the skald Hallar-Stein's "Rekstefja" and "Óláfsdrápa," perhaps from the late twelfth century. Oddr would not have cited them in his original Latin version because of the linguistic gulf, but he surely knew these poems or their sources. There were thus both ecclesiastical and secular strands in his information".
} 


\section{O Poder na Idade Média}

\section{Monarquias cristãs na Escandinávia medieval}

de martírio à moda hagiográfica, que é de todo muito coesa no que diz respeito aos esforços régio-missionários do personagem representado por Oddr, mas nunca deixam de reiterar os fazeres políticos de Olaf.

O historiador Sverre Bagge e a arqueóloga Sæbjørg Walaker Nordeide observaram uma tendência geral das narrativas medievais em exagerar os feitos e a importância de Olaf Tryggvason. Isso não foi exclusivo do trabalho de Oddr Snorrason, apesar de nele ter tomado grandes proporções, pela extensão do texto e pelo número de exemplos de feitura missionária. A anônima Historia Norwegie já contava que Olaf Tryggvason havia "convertido cinco países, sendo eles Shetland, ilhas Órcades e Faroé, Islândia e Groenlândia. A saga do monge Oddr também afirma que Olaf converteu o rei Vladimir de Rus e muitos de seu círculo ao cristianismo" (BAGGE; NORDEIDE, 2007, p. 157, tradução própria) ${ }^{12}$. Independentemente do quão bem sucedidos tenham sido os feitos cristianizadores de Olaf Tryggvason na materialidade de um passado inalcançável, nos debruçamos sobre as escolhas e os usos do passado empreendidos por Oddr Snorrason, que caminham na direção de construir um modelo régio.

\section{A formação das monarquias cristãs}

De acordo com Anders Winroth, a conversão da Noruega se deu pelas tentativas de diversos reis que se tornaram cristãos fora da Escandinávia, especialmente em incursões à Inglaterra, e retornaram à sua terra trazendo consigo a nova fé. Em seu retorno à Noruega, esses homens levaram consigo padres e bispos ingleses, através dos quais tentaram fincar as raízes no cristianismo em solo escandinavo. Boa parte dessas tentativas foram repelidas ou retardadas por chefes em disputas pelo poder

\footnotetext{
12 No original: "Have converted five countries, Shetland, the Orkney and Faroe Islands, Iceland and Greenland. Oddr Monk's saga also states that Olav converted King Vladimir of Rus' and many of his circle to Christianity".
} 


\section{O Poder na Idade Média}

\section{Guilherme Tavares Lopes Balau e Rodrigo Kmiecik}

local, como no caso de Olaf Tryggvason (WINROTH, 2012, p. 115-6). Entretanto, é importante ressaltar que a disputa entre o cristianismo e o paganismo é, em primeiro lugar, um motivo narrativo adotado pelos autores cristãos. As disputas de poder se dão especialmente no âmbito político, uma vez que, além de cristianizados, homens como Olaf Tryggvason retornam à Noruega com um novo modelo de exercício do poder, que pretendia limitar o poder dos chefes locais. A religião participa desse embate, mas em segundo plano, mais como um símbolo do que como causa desses conflitos.

O rei Olaf encontrou oposição nas espadas do earl norueguês e pagão Eiríkr Hákonarson e do rei sueco Olof Skötkonung, que coligaram forças e derrotaram Olaf Tryggvason na batalha de Svọlðr. Podemos observar a união entre um chefe pagão e um rei cristão para derrotar Olaf Tryggvason; logo, as disputas estão cravadas especialmente no que diz respeito ao poder político, ainda que, na perspectiva de Oddr Snorrason, o embate entre o cristianismo de Olaf e o paganismo generalizado daqueles que o enfrentam tem papel narrativo mais preponderante.

Segundo Theodore M. Anderson, o monge Oddr trabalhou o desfecho da vida de Olaf Tryggvason de modo a dar ecos de martírio à morte do rei.

Após um período de sucesso contra os pagãos na Noruega, Olaf finalmente sucumbe a uma conspiração pagã internacional. A saga foi comparada, por outros aspectos, à Canção de Rolando, mas também traça paralelos ao fato de que Olaf, assim como Rolando, é um trágico campeão cristão. Sua missão primordial é promover o cristianismo e combater o paganismo, em sua terra e além. Assim como Rolando é exaltado em seus últimos momentos, Olaf também assume perfil heroico conforme sua morte se aproxima. (ANDERSSON, 2006, p. 31-32, tradução própria) $)^{13}$

\footnotetext{
${ }^{13}$ No original: "after a period of successes against the pagans at home in Norway, Olaf finally succumbs to an international pagan conspiracy. The saga has been compared in other respects to The Song of Roland, but it also bears comparison to the extent that Olaf, like Roland, is a tragic Christian champion. His overriding mission is to promote Christianity and combat paganism, at home and abroad. Just as
} 


\section{O Poder na Idade Média}

Monarquias cristãs na Escandinávia medieval

$\mathrm{Na}$ discussão historiográfica, é necessário compreender as possibilidades de representação da figura régia quando se pensa no sentido de Olaf Tryggvason dado por Oddr Snorrason. São mais de duzentos anos que separaram o autor dos eventos narrados. Para o autor, Olaf fora um rei exemplar, figura responsável pela cristianização de sua terra - a Islândia - e símbolo da vitória cristã contra o paganismo. A percepção sobre Olaf na tradição até o período da escrita de sua biografia desenvolveuse de maneira bastante específica na Noruega e Islândia. Sua infância fora retratada como um paralelo às narrativas bíblicas e hagiográficas, bem como semelhante à concepção que se tinha dos reis-cristãos modelo, Clóvis e Constantino (BAGGE, 2006, p.480-1), e sua descendência apontada como direta de Haroldo I:

Naquele tempo, Hringaríki (Ringerike na Noruega) era comandada por Haraldr Grenski, que descendia de Guðrøðr, Bjǫrn, e Harald Fairhair, e era o pai de São Olaf; e por Tryggvi, que descendia de Óláfr e Harald Fairhair, e era o pai de Olaf Tryggvason (SNORRASSON, 2003, p. 36, tradução própria) ${ }^{14}$

As analogias e as referências à linhagens do passado, estabelecidas na narrativa, servem para legitimar a vida e as realizações de Olaf Tryggvason, apresentando sua posição de rei da Noruega como um título legítimo. Dada a importância dos chefes nas sociedades pré-cristãs, fosse na realização de rituais públicos ou na organização de expedições a outras terras, Oddr os percebe como importantes figuras detentoras de poder na formação social.

Roland is exalted in his final hours, so too does Olaf acquire a heroic profile when his time begins to ebb".

${ }^{14}$ No original: "At that time Hringaríki (Ringerike in Norway) was ruled by Haraldr grenski, who was descended from Guðrøðr, Bjǫrn, and Harald Fairhair and was the father of Saint Olaf; and by Tryggvi, who was descended from Óláfr and Harald Fairhair and was the father of Olaf Tryggvason". 


\section{O Poder na Idade Média}

\section{Guilherme Tavares Lopes Balau e Rodrigo Kmiecik}

As concepções a respeito de Olaf Tryggvason não são exclusivas da tradição islandesa da qual Oddr Snorrason faz parte. Adam de Bremen, cônego e cronista da arquidiocese de Hamburgo-Bremen, trouxe uma representação muito menos ideal frente ao arquétipo do rei missionário construído por Oddr, legado pela tradição norueguesa e islandesa. Na obra de Adam, existe certa desconfiança a respeito do cristianismo de Olaf, além de práticas associáveis às dos pagãos noruegueses: "Alguns relatam que Olaf havia sido um Cristão, outros que havia abandonado a Cristandade; todos, no entanto, afirmam que ele era hábil na adivinhação" (ADAM DE BREMEN, 1959, p. 82, tradução própria) $)^{15}$.

A concepção de Adam de Bremen vem da tradição narrativa dinamarquesa, na qual Olaf Tryggvason aparece como um antagonista na batalha de Svǫlðr. Para Adam, essa batalha resultou de uma aliança entre os reis da Dinamarca e da Suécia, que visavam proteger a cristandade ameaçada por Olaf; enquanto para Oddr Snorrason a batalha representa uma armadilha pagã tramada contra Olaf. Os diferentes propósitos de cada autor ao representar tais eventos residem em suas respectivas tradições narrativas, bem como em seus interesses e intenções de atribuir sentido ao passado. Adam de Bremen escreveu a crônica dos arcebispos de Hamburgo-Bremen para legitimar a posição da arquidiocese como autoridade religiosa da cristandade que se estabelecia nos reinos escandinavos, de modo que a figura de Olaf Tryggvason, convertido na Inglaterra, se afasta da autoridade e da centralização pretendida por Adam. Por outro lado, escrita na Islândia, a narrativa de Oddr Snorrason busca representar Olaf como um agente exitoso da cristianização entre os islandeses e os noruegueses.

\footnotetext{
${ }^{15}$ No original: "Some relate that Olaf had been a Christian, some that he had forsaken Christianity; all, however, affirm that he was skilled in divination".
} 


\section{O Poder na Idade Média}

\section{Monarquias cristãs na Escandinávia medieval}

Na saga, a figura de Olaf corresponde ao entendimento que se possui do processo de cristianização como um todo, no qual o batismo enquanto ferramenta de conversão teve um papel preponderante. Se por um lado a conversão individual de cada pessoa da sociedade pagã seria um longo e duradouro processo, passando por adaptações, reinterpretações e formas de entendimento do mundo que iam além dos dogmas católicos, a conversão de um rei possibilitou a institucionalização da igreja e a interiorização dos batismos. Nisso reside a importância da figura do rei missionário, força motriz da consolidação da cristandade nos reinos escandinavos (BAGGE, 2014, p. 69). A figura do rei cristão foi de papel preponderante na sociedade escandinava durante a formação das monarquias cristãs, nas esferas política, religiosa ou militar. Portanto, a conversão régia se tornou uma questão de identidade comum, de marco geral na memória, a qual os autores medievais ajudaram a cristalizar.

\section{As relações de poder na saga}

Os capítulos S22, S23 e S24 da Saga de Olaf Tryggvason foram numerados de acordo com o manuscrito preservado em Estocolmo. Na edição utilizada neste trabaIho, traduzida por Theodore M. Anderson e publicada pela Cornell University Press, esses textos aparecem entre os capítulos 30 e 32. Nesses episódios, Oddr Snorrason narra alguns dos feitos cristianizadores de Olaf Tryggvason ao longo da costa da Noruega.

No capítulo S22, o monge Oddr conta sobre a chegada de Olaf Tryggvason a Hǫrðaland (atual condado de Hordaland). Os homens mais notáveis da região reúnem-se em uma assembleia (Gulaping) para receber o rei. O líder da assembleia, um homem chamado QImóðr, faz um discurso antes da chegada de Olaf, no qual destaca: 


\section{O Poder na Idade Média}

\section{Guilherme Tavares Lopes Balau e Rodrigo Kmiecik}

Vocês sabem que um rei poderoso está a caminho desta região e desta assembleia. Ele vai querer fazer de nós seus súditos. O rei nos agrada de algumas maneiras, mas, de outras, suas práticas nos desagradam. Regozijamo-nos por sua força e eminência, e, no que diz respeito a essas qualidades, seria bom servir um rei como ele. Mas muito nos desagradam seus costumes estrangeiros. (SNORRASON, 2003, p. 79, tradução própria) ${ }^{16}$

Em um primeiro momento, Oddr escreve sobre a certa desconfiança que existe por parte dos homens de Hęrðaland quanto aos "costumes estrangeiros" do rei Olaf. Sendo esses chefes todos pagãos e habitantes da Noruega, referem-se ao cristianismo como algo estrangeiro, uma vez que Olaf Tryggvason converteu-se na Inglaterra.

No parágrafo seguinte, a voz de Oddr Snorrason parece falar mais alto que o líder Qlmóðr em seu próprio discurso: “Sei que ele [Olaf] tem uma irmã por parte de mãe chamada Ástríðr. Seu pai é Loðinn, que resgatou a mãe, com virilidade e bravura, de povos pagãos, entre os quais ela estava em terrível angústia" (SNORRASON, 2003, p. 79, tradução própria) ${ }^{17}$. Mesmo no discurso de Qlmóðr, a percepção de Oddr Snorrason se refere a outros povos não-cristãos como pagãos ${ }^{18}$ - mesmo o termo pagão sendo produto de um juízo de valor cristão sobre o outro - e ressalta que, entre eles, a mãe de Ástríðr sofria.

Assim, QImóðr propõe que, se Olaf Tryggvason estiver disposto a casar sua irmã Ástríðr com Erlingr, um dos chefes presentes em Hǫrðaland, então os homens es-

\footnotetext{
${ }^{16}$ No original: "You know that a powerful king is on his way to this region and this assembly. He will want to make us his subjects. The king pleases us in some ways, but in other ways his practices displease us. We are pleased by his strength and eminence, and with respect to these qualities it would be a good thing to serve such a king. But his foreign customs displease us greatly".

17 No original: "I understand that he has a sister by the same mother named Ástríðr. Her father is Loðinn, who rescued her mother with manliness and valor from heathen peoples, among whom she was in dire distress".

18 Oddr Snorrason não especifica quem são esses pagãos. Snorri Sturluson, no capítulo 52 da sua versão da saga (presente na Heimskringla) conta toda a história de Ástríðr. De acordo com Snorri, a mãe de Ástríðr havia sido capturada e vivia na Estônia, até Loðinn resgatá-la e torná-la sua esposa.
} 


\section{O Poder na Idade Média}

\section{Monarquias cristãs na Escandinávia medieval}

tariam de acordo a ouvir as palavras do rei. Nesse momento, a opinião de Qlmóðr a respeito da religião cristã mostra-se diferente mais uma vez, quando diz: "[...] bem como sua religião, que eu acredito ser boa" (SNORRASON, 2003, p. 79, tradução própria) ${ }^{19}$. Dentro da percepção de Oddr, é possível interpretar que a aceitação ou a recusa da fé cristã, para os pagãos de Hǫrðaland, depende de alianças políticas e das qualidades de nome e linhagem que poderiam continuar com tais legitimações entre os chefes, através do casamento.

Depois do discurso de Qlmóðr, o rei Olaf chega a Hǫrðaland e prega a palavra de Deus, mas os chefes se opõem à ideia de abandonar a religião de seus antepassados. Somente o fariam se o rei oferecesse algo em troca: o casamento de Ástríðr com Erlingr. Olaf Tryggvason julga a proposta como um bom negócio e aceita os termos, caso os homens se convertessem naquele mesmo instante. A aliança política com Hǫrðaland rende frutos missionários, de modo que, depois disso, a saga afirma que Olaf converteu centenas de homens em toda a região. No texto de Oddr, um dos traços que designa Olaf Tryggvason como um modelo régio é sua disposição para com alianças políticas relacionadas à conversão na Noruega.

Depois do episódio em Họrðaland, o rei segue para Vík, ao leste, e seus feitos na região são narrados no capítulo S23 da saga, evocando os mesmos sucedidos no capítulo anterior. Oddr Snorrason conta que em Vík governavam dois irmãos, Hyrningr e Porgeirr. O rei prega a palavra de Deus, a qual os chefes aceitam como verdadeira. Mas, para que abandonassem a crença de seu povo, gostariam de casarem-se com outras duas irmãs do rei, Ingigerðr e Ingiríðr. Os chefes dizem que "se você nos fizer homens tão poderosos, empenharemos toda nossa honra e esforço para pro-

\footnotetext{
19 No original: "And his religion as well, which I believe to be a good one".
} 


\title{
O Poder na Idade Média
}

\section{Guilherme Tavares Lopes Balau e Rodrigo Kmiecik}

mover sua autoridade" (SNORRASON, 2003, p. 80, tradução própria) ${ }^{20}$. A autoridade da qual falam os irmãos Hyrningr e Porgeirr é tanto política quanto religiosa, uma vez que muito imbricadas nas relações de poder desse contexto. Como desfecho, Olaf casa suas irmãs com os chefes e os nomeia duques da região após um grande festim. Snorrason destaca que, depois disso, todo o povo aceitou a fé cristã.

Com isso, o rei Olaf Tryggvason retorna a Prándheimr (atual condado de Trøndelag), para celebrar um grande festim durante o Yule, em Hlaðir. O evento é narrado no capítulo S24 da saga. Muitos chefes pagãos da região são convidados para a celebração. Em dado momento, o rei Olaf Tryggvason faz um pronunciamento:

\begin{abstract}
É bem sabido por todos vocês, chefes de Proendalęg, que sou cristão e anseio por uma religião diferente da qual vocês desejam seguir. Diminuí a importância dos seus deuses pois desejo abdicar de sua autoridade, para que, consequentemente, eu mantenha o meu próprio poder. Apesar disso, pretendo fazer como os reis de outrora fizeram pela prosperidade e honra dos deuses, homenageando-os nesse festim. Dizem que não há sacrifício tão aprazível quanto a matança de homens, que depois se banqueteiam com os deuses no salão de chefes, no outro mundo. Assim, pretendo oferecer vocês como um sacrifício aos deuses, para promover a paz para mim e a honra perpétua a vocês. Meus amigos estão agora do lado de fora desse salão, armados e preparados para seguir minhas ordens. Agora, escolham se preferem arriscar essa alternativa ou aceitar minha oferta. (SNORRASON, 2003, p. 81, tradução própria) ${ }^{21}$
\end{abstract}

\footnotetext{
${ }^{20}$ No original: "If you make us such powerful men, we will commit all our honor and effort to promoting your authority".

${ }^{21}$ No original: "It is well known to all of you chieftains in proendalog that I am a Christian and that I urge a religion different from the one you wish to have. I have diminished the standing of your gods because I would wish to shed their authority so that I might as a consequence maintain my rule. Notwithstanding, I intend to do as former kings did for the prosperity and honor of the gods, and I wish to do homage to them at this feast. You say that no sacrifice is so pleasing to them as the killing of men who then feast with them in the other world in the hall of the chieftain of the gods. I now intend to offer you as a sacrifice to them to promote peace for myself and perpetual honor for you. My friends are now standing outside the hall with weapons at the ready and prepared to do whatever I want. Now choose whether you wish to risk this alternative or do my bidding".
} 


\section{O Poder na Idade Média}

\section{Monarquias cristãs na Escandinávia medieval}

A alternativa de ameaça aos chefes é a de morrer pelas espadas dos homens de Olaf Tryggvason, mas, para evitar a matança, o rei propõe uma oferta. Oddr Snorrason narra que todos os chefes pagãos entram em desalento por causa das palavras do rei, e este, percebendo ganhar-Ihes pela ameaça, ironiza sobre seu paganismo: "por que estão agora tão abatidos? Têm medo de morrer, e agora pensam que isso não seria algo tão bom quanto dizem? Pois agora devem aceitar o batismo, ou juntem-se aos seus deuses" (SNORRASON, 2003, p. 81, tradução própria) ${ }^{22}$. De maneira muito menos diplomática que nos episódios analisados anteriormente, Olaf Tryggvason força a conversão dos chefes de prándheimr com uma oferta que eles não podem recusar. Neste trecho, ainda que não alcançados por alianças de casamentos e nomeações, os êxitos cristianizadores de Olaf ainda se dão no âmbito político, através de uma coerção de força militar contra os chefes pagãos. Depois do festim, Oddr Snorrason narra que os chefes são batizados na véspera de Natal.

Na saga, além do evidente conflito de Olaf Tryggvason com os chefes, a oposição entre o cristianismo e o paganismo também se dá no âmbito simbólico. Podemos notar que, no início do capítulo S24, as comemorações giram em torno do Yule, um dos principais ritos pagãos entre os escandinavos daquele período, e Oddr se preocupa em mencioná-lo para posteriormente cravar uma oposição. Quando convertidos os chefes, o marco festivo dado por Oddr não é mais a festa pagã, mas o Natal cristão, explicitando os valores impostos por Olaf.

Além disso, as vantagens em adotar a fé cristã são explicitadas pelo autor. É dito que, após convertidos, os chefes são fortalecidos pelos mandamentos de Deus, além de receberem grandes presentes em dinheiro. Ao fim, Oddr Snorrason reitera

\footnotetext{
22 No original: "Why are you now so downcast? Are you afraid to die, and do you think it is not such a good thing as you say? Now you should either accept baptism or go to join your gods".
} 


\section{O Poder na Idade Média}

\section{Guilherme Tavares Lopes Balau e Rodrigo Kmiecik}

que "a cristandade divina foi amplamente fortalecida pelas súplicas do rei Olaf" (SNORRASON, 2003, p. 81, tradução própria) ${ }^{23}$. De acordo com a nota de Theodore M. Andersson na versão que consultamos para a elaboração deste trabalho, em outro manuscrito da Saga de Olaf Tryggvason - o manuscrito AM $3104^{\circ}$ - esse mesmo evento termina com outra sentença: "todos eles clamaram o nome do Senhor. E o diabo viu sua honra muito enfraquecida à medida que a ordem de Deus cresceu" (SNORRASON apud ANDERSON, 2006, p. 143, tradução própria) ${ }^{24}$. Ambas as versões exaltam os êxitos cristianizadores, mas, na versão do AM $3104^{\circ}$, a saga evoca ainda outro poderoso conflito simbólico entre paganismo e cristianismo, com a analogia mais expressiva em toda a literatura da cristandade medieval: o embate entre Deus e o diabo.

Em uma obra como a Saga de Olaf Tryggvason, escrita por um monge do século XII, espera-se a significação do paganismo como algo que diz respeito às forças do mal e do diabo; dos pagãos como feiticeiros, como um "outro" religioso. Existem mais exemplos desse embate ao longo da saga, como a aparição do deus Odin como uma figura diabólica no capítulo 43, a destruição de um altar para Freya empreendida por Olaf no capítulo 46, e um episódio especialmente visceral e simbolicamente muito poderoso no capítulo 56, em que se lê:

Aconteceu em uma assembleia na mesma região onde o rei estava pregando sua fé, quando um homem poderoso e eloquente se opôs a ele. O rei mandou prendê-lo e ordenou que introduzissem uma pequena cobra pela sua boca. Isso foi feito. Pegaram a serpente e abriram a boca do homem, mas ele cuspiu a cobra, e ela saiu, se contorcendo para todas as direções que não fossem a boca do homem. Então o rei pegou um pedaço de ferro quente e apertou-o contra a serpente. Quando sentiu o calor, a cobra entrou pela boca do homem, contorceu-se por suas entranhas, e depois saiu. A cobra trazia o coração do

\footnotetext{
23 No original: "God's Christianity was greatly strengthened at King Olaf's urging".

${ }^{24}$ No original: "They all called on the name of the Lord. And the devil saw his honor much diminished as God's rule grew".
} 


\section{O Poder na Idade Média}

\section{Monarquias cristãs na Escandinávia medieval}

homem em sua boca, e quando isso foi visto, grande medo e terror instaurouse entre todo aquele povo pagão (SNORRASON, 2003, p. 106, tradução própria) ${ }^{25}$

Novamente é mostrado o confronto entre o cristianismo e o paganismo, dessa vez através de uma punição violenta pela oposição à cristianização. Mas além do assassínio mostrado na passagem, pelo qual o medo e o terror são elementos importantes no confronto contra o paganismo, há também outra carga simbólica trabalhada por Oddr Snorrason: a serpente. Na Bíblia, importante componente na construção das mentalidades medievais, a serpente constantemente aparece como representação maléfica, amaldiçoada por Deus no Gênesis: “Porque fizeste isso és maldita entre todos os animais domésticos e todas as feras selvagens. Caminharás sobre teu ventre e comerás poeira todos os dias de tua vida." (Gn 3,14, 2016, p. 37). No Apocalipse, a serpente aparece diretamente análoga ao diabo: “Foi expulso o grande Dragão, a antiga Serpente, o chamado Diabo ou Satanás, sedutor de toda a terra habitada" (Ap 12,9, 2016, p. 2154). Ao longo da Idade Média, na produção textual e imagética, muitas vezes as serpentes serviram como motivo retórico dentro do pensamento analógico ${ }^{26}$ para simbolizar qualquer oposição a Deus, significadas como dragões ou símbolos do mal e da mentira, que evocam o Diabo ou o paganismo. Ao lermos o capítulo 56 da saga, é possível interpretar que a cena constrói uma metáfora de perdição, através da analogia entre a cobra e o paganismo, de modo que o pagão assassinado

\footnotetext{
${ }^{25}$ No original: "It happened at an assembly in the same region that the king was preaching the faith and that a mighty and eloquent man opposed him. The king had him seized and ordered that they make a small snake wriggle into his mouth. That was done. They took the snake and opened the man's mouth, but he exhaled toward the snake, and it wriggled away from his mouth and was bent on any course other than to enter his mouth. Then the king had an iron heated and tied to the snake. When it felt the heat, it entered his mouth and wriggled right down into his belly and then out. It had the man's heart in its mouth, and when this was seen, there was great fear and terror among all the heathen people".

${ }^{26}$ A respeito do conceito de pensamento analógico medieval, ver JúNIOR, Hilário Franco. Similibus simile cognoscitur. O pensamento analógico medieval. Medievalista online, n. 14, 1 jul. 2013.
} 


\section{O Poder na Idade Média}

\section{Guilherme Tavares Lopes Balau e Rodrigo Kmiecik}

morre por causa da serpente, logo, por causa do seu paganismo - o que é uma verdade tanto simbólica quanto literal, afinal, o homem confrontado por Olaf Tryggvason é morto por não aceitar a cristianização.

\section{Considerações finais}

A cristianização da Escandinávia foi um processo lento que se deu ao longo de muitos séculos. Os primeiros esforços missionários começam com Ansgar e Rimbert, ainda no século IX, e se estendem até a conversão dos reis ao longo do século XI. Olaf Tryggvason se converteu na Inglaterra nos fins do século X e, ao retornar à Noruega, tentou espalhar entre seu povo a fé cristã. Dois séculos depois, ao fim do século XII, a vida do rei Olaf tornou-se assunto principal do trabalho de Oddr Snorrason, ao escrever sua Saga de Olaf Tryggvason, na qual vasculhou, interpretou e significou o passado a seus propósitos.

De acordo com Anders Winroth, a conversão da Escandinávia foi normalmente abordada como um evento muito claro e definindo pelas narrativas medievais. Isso porque a maioria das narrativas "foram escritas para louvar as virtudes de certos indivíduos, como Olaf Tryggvason e Ansgar" (WINROTH, 2012, p. 128, tradução própria). Por volta de 1150, os reinos escandinavos já eram amplamente cristãos. Oddr escreve a saga nos fins do século, por volta de 1180. O autor islandês representa o passado escrevendo em um tempo no qual as monarquias cristãs - antes ameaçadas pelo paganismo e por conflitos que envolviam as relações de poder eclesiástico e político - agora firmam-se consolidadas.

Sempre haverá uma nova perspectiva a ser representada pela análise do historiador, provando a dinamicidade inerente ao conhecimento histórico. Por meio da relação com seu tempo, Oddr Snorrason possibilita a interpretação em um longo con- 


\section{O Poder na Idade Média}

Monarquias cristãs na Escandinávia medieval

tínuo que é o estudo das ideias, contribuindo para o entendimento da formação, intenção e construção do passado pelas lentes dos sujeitos que sofrem as experiências do tempo. O rei Olaf Tryggvason representado na biografia escrita por Oddr é, antes de tudo, um produto da concepção do monge a respeito do passado escandinavo, construída através dos séculos pela dinâmica das narrativas.

Mesmo durante e após o reinado de Olaf Tryggvason, a cristandade escandinava permaneceu vacilante por muito tempo, mas tem em Olaf um marco inicial. Oddr Snorrason não busca evidenciar os reveses dessa experiência histórica sobre o tempo do qual fala; mostra os êxitos de uma cristianização totalizante imaginada, que tem em Olaf o principal agente vitorioso contra o paganismo. Portanto, a leitura da Óláfs saga Tryggvasonar nos permite pensar as concepções de seu autor a respeito das relações de poder na Escandinávia medieval, bem como as implicações da consolidação das monarquias cristãs na região. Partindo da conversão dos chefes pelo casamento com irmãs do rei, a coerção dos chefes pagãos por meio da força, entre outros artifícios simbólicos da construção do passado realizada por Oddr Snorrason, concluímos que na saga o triunfo cristão contra o paganismo é ambivalente: eleva os feitos missionários e reitera os êxitos políticos de Olaf Tryggvason.

\section{Fontes}

ADAM DE BREMEN; TSCHAN, Francis J. (translator). History of the archbishops of Hamburg-Bremen. New York: Columbia University Press, 1959.

BÍBLIA DE JERUSALÉM. São Paulo: Paulus, 11ª reimpressão, 2016.

SNORRASON, Oddr; ANDERSSON, Theodore M. (translator). The Saga of Olaf Tryggvason. Ithaca, New York: Cornell University Press, 2003. 


\section{O Poder na Idade Média}

Guilherme Tavares Lopes Balau e Rodrigo Kmiecik

\section{Referências bibliográficas:}

ANDERSSON, Theodore M. The Growth of the Medieval Icelandic Sagas, 1180-1280. Ithaca, Nova York, Cornell University Press, 2006.

BAGGE, Sverre; NORDEIDE, Sæbjørg Walaker. The kingdom of Norway. In: BEREND, Nora (ed.). Christianization and the Rise of Christian Monarchy: Scandinavia, Central Europe and Rus' c. 900-1200. New York: Cambridge University Press, 2007, p. 121166.

BAGGE, Sverre. Cross and Scepter: The Rise of the Scandinavian Kingdoms from the Vikings to the Reformation. Princeton: Princeton University Press, 2014.

. The Making of a Missionary King: The Medieval Accounts of Olaf Tryggvason and the Conversion of Norway. The Journal of English and Germanic Philology, v.105, n.4, out/2006, p. 473-513.

BARREIRO, Santiago. Las sagas políticas: sagas de reyes y sagas contemporáneas. In: BARREIRO, Santiago; BIRRO, Renan (org.). El mundo nórdico medieval: una introducción. Ciudad Autónoma de Buenos Aires: Luciana Mabel Cordo Russo, 2017, p. 161178.

BARREIRO, Santiago. Los géneros de la literatura medieval islandesa. In: BASARTE, Ana; RUSSO, Luciana Cordo (org.). Géneros literarios medievales. Buenos Aires: Eudeba, 2019, p. 169-182.

GOETZ, Hans-Werner. Constructing the Past: Religious dimensions and historical consciousness in Adam of Bremen's Gesta Hammaburgensis ecclesiae pontificum. In: MORTENSEN, Lars Boje (Ed.). The Making of Christian Myths in the Periphery of Latin Christendom. Copenhagen: Museum Tusculanum Press University of Copenhagen, 2006, p. 17-51

Historical Writing, Historical Thinking and Historical Consciousness in the Middle Ages. Revista Diálogos Mediterrânicos, n.2, maio/2012, p. 110-128.

The Concept of Time in the Historiography of the Eleventh and Twelfth Centuries. In: ALTHOFF, Gerd; FRIED, Johannes; GEARY, Patrick J. Medieval Concepts of the Past: Ritual, Memory, Historiography. Cambridge: Cambridge University Press, 2003, p. 139-165. 


\section{O Poder na Idade Média}

Monarquias cristãs na Escandinávia medieval

GRZYBOWSKI, Lukas. Uma 'Terceira Via' para o Estudo das Idéias Políticas: A Vorstellungsgeschichte como resposta aos problemas colocados pela Cambridge School of the History of Political Thought. Revista Diálogos Mediterrânicos, n.3, nov/2012, p.143-159.

HERMANN, Pernille. Concepts of Memory and Approaches to the Past in Medieval Icelandic Literature. Scandinavian Studies, Vol. 81, No. 3, 2009, p. 287-308.

RÜSEN, Jörn. Razão histórica: teoria da história: fundamentos da ciência histórica. Tradução de Estevão de Rezende Martins. Brasília: Editora Universidade de Brasília, 2001.

WINROTH, Anders. The conversion of Scandinavia: Vikings, merchants, and missionaries in the remaking of Northern Europe. New Haven: Yale University Press, 2012. 